\title{
Retrospective analysis of treatment modalities in diabetic muscle infarction
}

\author{
Ikenna Onyenemezu' \\ Eugenio Capitle Jr ${ }^{1,2}$ \\ 'Department of Medicine, ${ }^{2}$ Allergy/ \\ Immunology Rheumatology Division, \\ University of Medicine and Dentistry \\ of New Jersey, Newark, NJ, USA
}

This article was published in the following Dove Press journal:

Open Access Rheumatology: Research and Reviews

10 January 2014

Number of times this article has been viewed

Background: Diabetic muscle infarction (DMI) is a spontaneous necrosis of skeletal muscle of unknown etiology. The major risk factor is longstanding uncontrolled diabetes mellitus (DM). Optimal treatment for DMI is not known. The purpose of this study was to analyze the outcome of surgical treatment, physiotherapy, and bed rest in DMI.

Methods: We searched Medline from its inception to April 2013. We selected cases that provided sufficient data on recovery duration, recurrences, and non-recurrences. Baseline characteristics, including age, sex, microvascular complications, lesion size estimated on magnetic resonance imaging, type of diabetes, and duration of diabetes were assessed. The primary outcome was mean time to recovery from initial treatment and secondary outcomes were mean time to recurrence and recurrence rate.

Results: Mean time to recovery was 149 (95\% confidence interval [CI] 113-186), 71 (95\% CI 47-96), and 43 (95\% CI 30-57) days for surgery, physiotherapy and bed rest, respectively. These figures were statistically significant only for surgery versus physiotherapy and surgery versus bed rest $(P<0.01)$. Mean time to recurrence was 30,107, and 297 days for surgery, physiotherapy, and bed rest, respectively. The recurrence rate was $57 \%, 44 \%$, and $24 \%$ for surgery, physiotherapy, and bed rest, respectively.

Conclusion: Our results show a similar outcome for physiotherapy as compared with bed rest. It also confirms nonsurgical treatment as a better therapeutic option compared with surgical treatment.

Keywords: therapy, infarction, diabetes, complications, comparison

\section{Introduction}

Diabetic muscle infarction (DMI) refers to spontaneous ischemic necrosis of skeletal muscle that is not related to major arterial thromboembolism. DMI was first described in 1965 by Angervall and Stener, who demonstrated that this condition is ischemic in nature and may be secondary to diabetic microangiopathy and arteriosclerosis. ${ }^{1} \mathrm{DMI}$ occurs in patients with longstanding uncontrolled diabetes mellitus (DM), who have underlying microvascular complications. ${ }^{2-6}$ The average age at onset is approximately 44 (range 19-81) years, with both sexes equally affected. ${ }^{7}$

The pathogenesis of DMI is not fully understood, and numerous theories have been suggested, including coagulation-fibrinolysis abnormalities, hypoxia-reperfusion events, and diabetic microangiopathy with arteriosclerosis. ${ }^{1,8-11}$ Fibrosis and apoptosis have been shown to be features of long-term myocardial damage in experimental type 1 DM. ${ }^{12}$ Patients present with an acute onset of painful swelling of the affected muscle with subsequent appearance of a palpable painful mass. ${ }^{7,13}$ Systemic signs are often

Correspondence: Ikenna Onyenemezu University of Medicine and Dentistry of New Jersey, 90 Bergen Street, Suite 4500, Newark, NJ 07I03, USA Tel +l 9739722500

Fax + I 9739722769

Email andre740@gmail.com

Open Access Rheumatology: Research and Reviews 2014:6 I-6

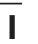


absent, and laboratory findings are varied and nonspecific. The thigh muscles are the most commonly involved muscle group. ${ }^{2-5}$ Typical magnetic resonance imaging (MRI) findings on T2-weighted imaging include high signal intensity in the infarcted muscle with subcutaneous and subfascial edema. ${ }^{3,10,14-20}$ Histologic findings are nonspecific, and usually show large areas of muscle necrosis with varying degrees of edema, regenerating muscle fibers, polymorphonuclear leukocyte cells, and hemorrhage. ${ }^{21}$ The diagnosis is established based on the overall clinical picture and MRI findings. Biopsy is generally not recommended and is reserved for atypical cases. The short-term prognosis of DMI is good, but the long-term prognosis is poor due to underlying advanced microvascular disease in patients with this condition. . $^{8,922,23}$

The management modalities for DMI that are widely reported in the literature are bed rest and physiotherapy. The treatment outcome and favorability of these are based on limited evidence and expert opinion, and the outcomes reported for physiotherapy are inconsistent. Therefore, in order to better elucidate the data on this topic, we analyzed and compared treatment outcomes for surgery, physiotherapy, and bed rest in DMI. Physiotherapy and bed rest are general descriptive terms used for all forms of immobility and physical therapy. Surgery denotes that a muscle or part of a muscle is excised.

\section{Materials and methods Data selection}

We searched Medline from its inception to April 2013 using the key terms "diabetic muscle infarction" and all synonyms and associated words; bibliographies in the reports obtained were reviewed. From the search results, we selected cases that provided sufficient data on recovery duration, recurrences, and non-recurrences. Cases were included in the final analysis if the clinical presentation was sufficiently described, MRI or computed tomographic images of the lesion were documented, and the patient underwent only a single therapy (ie, surgery alone, physiotherapy alone, or bed rest alone). We excluded cases that had not adequately eliminated trauma, infection, tumor, myositis, and deep vein thrombosis as possible causes. The clinical data used to establish baseline characteristics were age, sex, microvascular complications (nephropathy, retinopathy, and neuropathy), number of muscles involved, type of diabetes, and duration of diabetes. Laboratory findings, including glycosylated hemoglobin $\left(\mathrm{HbA}_{1 \mathrm{c}}\right)$, creatine kinase level, erythrocyte sedimentation rate, and white cell count, were documented when available. $\mathrm{HbA}_{1 \mathrm{c}}$, erythrocyte sedimentation rate, and creatine kinase values obtained were those provided during the initial evaluation. Baseline characteristics and laboratory parameters are summarized in Table 1.

\section{Data analysis}

The outcomes in the three treatment modality groups are presented as mean time to recovery, mean time to recurrence, and one-year recurrence rate. Mean time to recovery is defined as the average time interval between initiation of treatment and complete recuperation (near or complete resolution of symptoms). Mean time to recurrence is the average time interval between complete recuperation and

Table I Baseline characteristics $2,3,7-9,13,15,16,18-22,24-56$

\begin{tabular}{|c|c|c|c|c|}
\hline Items & Surgery & Physiotherapy & Bed rest & $P$-values \\
\hline Percent female & $6 / 8(75.0 \%)$ & I2/25 (48.0\%) & 19/32 (59.4\%) & 0.52 \\
\hline Mean age (years) & $4 \mid(n=8)$ & $42(n=25)$ & $43(n=32)$ & $N S^{a}$ \\
\hline Mean duration of DM (years) & $18.3(n=6)$ & $13.7(n=2 \mid)$ & $14.3(n=27)$ & $N S^{a}$ \\
\hline Percent type I DM & $4 / 7(57.1 \%)$ & $8 / 15(53.3 \%)$ & 17/32 (53.1\%) & 0.99 \\
\hline MV complication: nephropathy & $6 / 7(85.7 \%)$ & 10/15 (66.7\%) & $25 / 29(86.2 \%)$ & 0.87 \\
\hline MV complication: neuropathy & $5 / 7(71.4 \%)$ & $10 / 14$ (69.2\%) & I5/26 (57.7\%) & 0.90 \\
\hline MV complication: retinopathy & $6 / 7(85.7 \%)$ & 6/14 (38.5\%) & $20 / 26(76.9 \%)$ & 0.54 \\
\hline \multicolumn{5}{|l|}{ Number of muscles ${ }^{b}$ involved } \\
\hline I & I/8 (I2.5\%) & $\mathrm{I} / \mathrm{I} 2(8.3 \%)$ & II/3I (35.5\%) & 0.33 \\
\hline 2 & $3 / 8(37.5 \%)$ & $4 / 12(33.3 \%)$ & $5 / 31(16.1 \%)$ & \\
\hline$\geq 3$ & $4 / 8(50.0 \%)$ & $7 / 12$ (58.3\%) & $|5 / 3|(48.4 \%)$ & \\
\hline $\mathrm{HbA}_{\mathrm{lc}}>6.5 \%$ & $\mathrm{I} / \mathrm{I}$ & $2 / 4$ & $13 / 17$ & \\
\hline ESR $>20 \mathrm{~mm} /$ hour & $5 / 5$ & $6 / 6$ & $19 / 21$ & \\
\hline $\mathrm{CK}>200 \mathrm{IU} / \mathrm{L}$ & $2 / 6$ & $3 / 10$ & $9 / 24$ & \\
\hline WBC $>12 \times 10^{9}$ cells $/ \mathrm{L}$ & $1 / 6$ & $2 / 10$ & $6 / 23$ & \\
\hline
\end{tabular}

Notes: ${ }^{a} N S$, not statistically significant (surgery versus bed rest, $P>0.05$; surgery versus physiotherapy, $P>0.05$; physiotherapy versus bed rest, $P>0.05$ ); ${ }^{b}$ umber of muscles involved was obtained from MRI.

Abbreviations: DM, diabetes mellitus; CK, creatine kinase; MV, microvascular; MRI, magnetic resonance imaging; ESR, erythrocyte sedimentation rate; WBC, white blood cell count; $\mathrm{HbA}_{\mathrm{Ic}}$, glycosylated hemoglobin; NS, not statistically significant. 
first episode of recurrence. Recurrence rate is defined as first episode of recurrence within one year. The categorical statistical variables are first episode of recurrence, no recurrence, lesion size, sex, microvascular complications, and type of DM; continuous variables are recovery duration, recurrence-free duration, patient age, and duration of DM. We assessed for differences between baseline characteristics using the chi-square test, Fisher's exact test, Student's $t$-test, and Tukey's test as appropriate. We performed pairwise comparisons of mean time to recovery between the three treatment modality groups using Tukey's test post analysis of variance with adjusted $P$-values for multiple comparisons; a similar analysis was done for mean time to recurrence. Pairwise comparison of recurrence rate was performed using Fisher's exact test. All reported $P$-values are two-sided.

\section{Results}

In total, 80 citations were obtained and fully reviewed; 34 of these were rejected for analysis based on our inclusion/exclusion criteria. A total of 46 references,

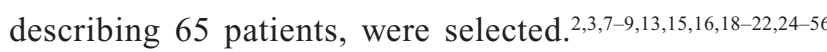
Overall, 32 patients were treated with bed rest, 25 received physiotherapy, and eight underwent surgical excision of the infarcted muscle. Nearly all patients were placed on a rigorous glycemic control regime following diagnosis of DMI. Baseline characteristics were similar between the three groups (Table 1). The types of DM were in an approximately 1:1 ratio between the three groups; the mean patient age was 41,42 , and 44 years for surgery, physiotherapy, and bed rest, respectively; more than $60 \%$ of patients in each treatment group had involvement of two or more muscles. Approximately $67 \%$ and $29 \%$ of the muscle groups involved the thigh and calf, respectively. The rest comprised foot, lower back, and proximal upper limb muscles.

The primary outcome, ie, mean time to recovery, was 149 (95\% confidence interval [CI] 113-186), 71 (95\% CI 47-96), and 43 (95\% CI 30-57) days for surgery, physiotherapy, and bed rest, respectively. These were only statistically significant for surgical treatment compared with physiotherapy $(P<0.01)$ and surgical treatment compared with bed rest $(P<0.01$, Figure 1$)$. The secondary outcome, ie, mean time to recurrence, was 30, 107, and 297 days for surgery, physiotherapy, and bed rest, respectively; a cross group pairwise comparison was not statistically significant $(P>0.05$, Figure 2$)$. The recurrence rate within one year was $57 \%$ (4/7) for surgery, $44 \%$ (4/9) for physiotherapy, and $24 \%$ (4/17) for bed rest $(P=0.52$, Figure 3). A subgroup analysis of patients in the bed rest group comparing mean time to

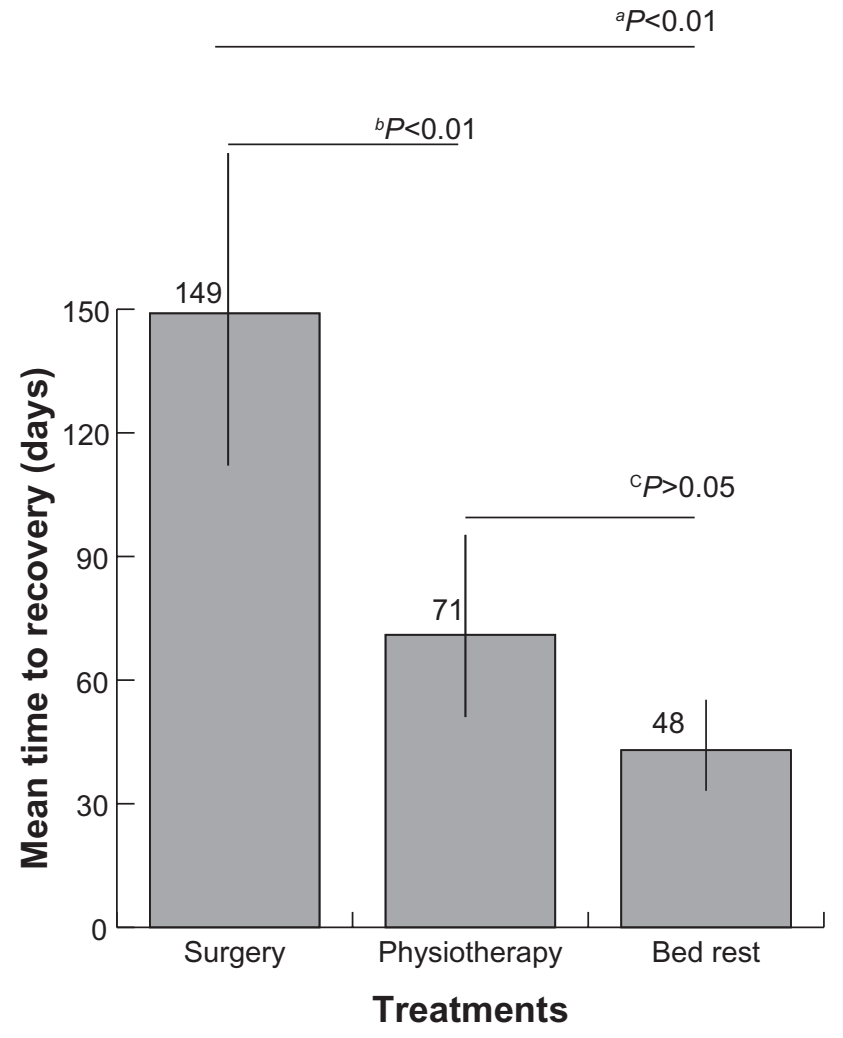

Figure I Mean time to recovery.

Notes: Mean time to recovery following surgery, physiotherapy, and bed rest in days. Bed rest has the shortest time to recovery followed by physiotherapy, then

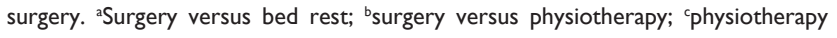
versus bed rest. $P$ is adjusted for multiple comparisons.

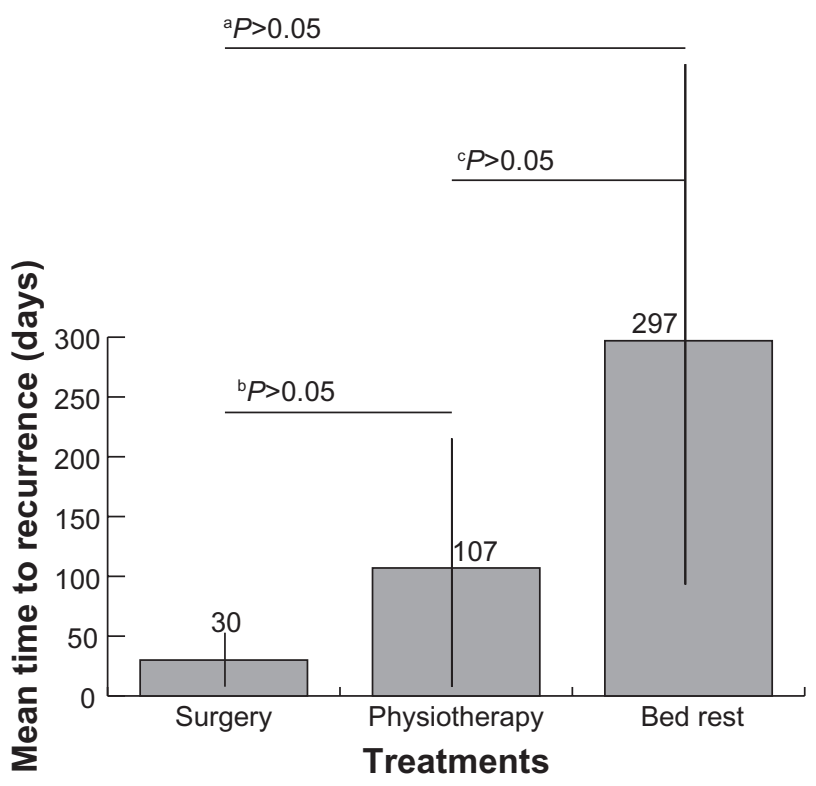

Figure 2 Mean time to recurrence.

Notes: Mean time to recurrence after surgery, physiotherapy, and bed rest in days. Bed rest has the longest duration of well interval followed by physiotherapy, then

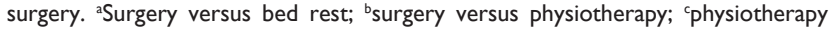
versus bed rest. $P$ is adjusted for multiple comparisons. 


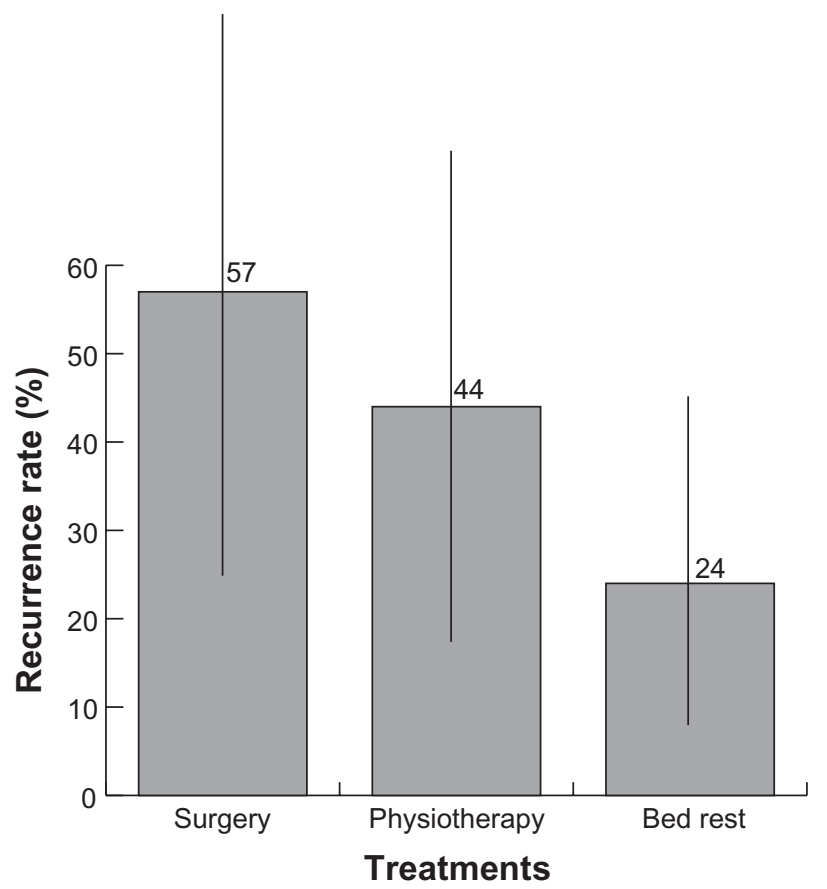

Figure 3 Recurrence rate within one year.

Notes: Recurrence rate within one year for surgery, physiotherapy, and bed rest. Bed rest has the lowest recurrence rate followed by physiotherapy, then surgery $(P=0.52)$. Vertical bars represent confidence intervals.

recovery between those who underwent incision biopsy versus no biopsy showed a trend toward faster recovery in patients without biopsy ( 49 days versus 40 days, $P=0.54$ ).

\section{Discussion}

DMI is a seemingly rare complication of DM, but is probably underdiagnosed. This analysis is unique because it is the first to analyze outcomes of physiotherapy compared with other modalities. Our results show that physiotherapy has a treatment outcome comparable with that of bed rest, based on our primary and secondary outcomes. The outcome of surgery, on the other hand, was a more prolonged recovery duration that was statistically significant compared with the recovery duration with physiotherapy and bed rest. The latter finding confirms the report by Kapur and McKendry. ${ }^{57}$ In general, there is a trend toward better outcomes with bed rest than with physiotherapy and surgery in regard to both primary and secondary outcomes (Figures 1-3).

A subgroup analysis of the bed rest group that compared outcomes in patients who underwent incision biopsy with those in patients with no biopsy showed a trend toward reduced recovery duration for the no biopsy group, although this result was not statistically significant. Excision biopsy is commonly associated with worsening symptoms and prolonged recovery duration, so is generally discouraged. ${ }^{19,58,59}$ If a confirmatory biopsy is warranted, needle biopsy is recommended because it has been observed to be well tolerated. ${ }^{9,59}$

The optimal treatment for DMI is still unknown, and current treatment practices are based on limited evidence. Prolonged bed rest leads to deconditioning, joint contractures, and thromboembolic disease ${ }^{40,60}$ on the other hand, a vigorous exercise regime prescribed during the acute or postoperative period will perpetuate inflammation, disrupt the healing process, and ultimately result in a prolonged recovery. ${ }^{9,42,59}$ When a judicious exercise regime is undertaken at the appropriate time, deconditioning can be prevented and muscle tissue regeneration is promoted. ${ }^{60}$ Therefore, the optimal therapy for DMI may be a period of bed rest during the acute phase followed by gentle physiotherapy as tolerated.

Other treatment modalities that have been tried include antibiotics, corticosteroids, and anticoagulants. Data on each of these are limited, but when reported, these treatment modalities are usually used in combination ${ }^{5,11,42,58,61-63}$ or for a specific primary clinical purpose (eg, deep vein thrombosis, infection) in the setting of DMI. . $^{42,42,63,64}$ The rationale behind use of anticoagulation for DMI is the hypothesis that DMI is caused by an acquired hypercoagulable state; ${ }^{40,42,63}$ autopsy studies in reported cases have not shown thromboembolus, but have shown diffuse arteriosclerosis and microangiopathy. ${ }^{1,9}$ The hypercoagulable state hypothesis alone does not sufficiently account for the pathogenesis of DMI, given that the condition is rare. Nearly all patients with DMI have uncontrolled DM; in this setting, systemic steroid therapy will exacerbate hyperglycemia. This risk in diabetic patients with multiple microvascular complications will likely exceed any unproven benefit. Platelet hyperaggregability, as demonstrated by Rajkumar et al, is the primary rationale for use of antiplatelet agents as potential therapy for reducing the rate of recurrence of DMI. ${ }^{63}$ Although data are few, reduction in recurrence has been documented in cases that involved bed rest. ${ }^{6,61,63,65}$ Lastly, there were limited data on crossover therapy in the treatment modality groups.

The primary limitation of this study is its retrospective nature and strict inclusion/exclusion criteria, which introduces bias in data gathering and reporting. Further, this study is underpowered due to its small sample size; as a result, some effects of practical significance may not have been identified. It could be that the trend towards a better outcome with bed rest is real but statistically insignificant due to the small sample size. Scarce and poorly reported data on antiplatelet therapy and crossover studies resulted in a 
limited analysis on these topics. Confounding variables that have been inconsistently reported (eg, other chronic medical conditions) may have played a significant role in the overall outcome in ways that are not readily quantified. With the data available, the baseline characteristics that were reported are similar between the three groups.

In summary, the optimal treatment for DMI is still unclear, and the current practice is based on limited evidence and expert opinion. Our results show a similar treatment outcome with physiotherapy compared with bed rest. They also confirm that nonsurgical treatment is a better therapeutic option than surgical treatment. This information serves to clarify the data on this topic.

\section{Acknowledgment}

We acknowledge the department of quantitative methods at the University of Medicine and Dentistry of New Jersey for reviewing the statistical analysis.

\section{Disclosure}

The authors report no conflict of interest in this work.

\section{References}

1. Angervall L, Stener B. Tumoriform focal muscular degeneration in two diabetic patients. Diabetologia. 1965;1:39-42.

2. Kapur S, Brunet JA, McKendry RJ. Diabetic muscle infarction: case report and review. J Rheumatol. 2004;31:190-194.

3. Aboulafia AJ, Monson DK, Kennon RE. Clinical and radiological aspects of idiopathic diabetic muscle infarction. Rational approach to diagnosis and treatment. J Bone Joint Surg Br.1999;81:323-326.

4. Trujillo-Santos AJ. Diabetic muscle infarction: an underdiagnosed complication of long-standing diabetes. Diabetes Care. 2003;26: 211-215.

5. Lafforgue P, Janand-Delenne B, Lassman-Vague V, Daumen-Legre V, Pham T, Vague P. Painful swelling of the thigh in a diabetic patient: diabetic muscle infarction. Diabetes Metab. 1999;25:255-260.

6. Grigoriadis E, Fam AG, Starok M, Ang LC. Skeletal muscle infarction in diabetes mellitus. J Rheumatol. 2000;27:1063-1068.

7. Morcuende JA, Dobbs MB, Crawford H, Buckwalter JA. Diabetic muscle infarction. Iowa Orthop J. 2000;20:65-74.

8. Mukhopadhyay P, Barai R, Phillips CA. An usual case of myonecrosis. Case Rep Endocrinol. 2011;2011:ID624020.

9. Chester CS, Banker BQ. Focal infarction of muscle in diabetics. Diabetes Care. 1986;9:623-630.

10. Huang BK, Monu JU, Doumanian J. Diabetic myopathy: MRI patterns and current trends. AJR Am J Roentgenol. 2010;195:198-204.

11. Silberstein L, Britton KE, Marsh FP, Raftery MJ, D'Cruz D. An unexpected cause of muscle pain in diabetes. Ann Rheum Dis. 2001;60:310-312.

12. Ares-Carrasco S, Picatoste B, Benito-Martin A, et al. Myocardial fibrosis and apoptosis, but not inflammation, are present in long-term experimental diabetes. Am J Physiol Heart Circ Physiol. 2009;297: H2109-H2119.

13. Melikian N, Bingham J, Goldsmith DJ. Diabetic muscle infarction: an unusual cause of acute limb swelling in patients on hemodialysis. $\mathrm{Am}$ J Kidney Dis. 2003;41:1322-1326.

14. Khoury NJ, el-Khoury GY, Kathol MH. MRI diagnosis of diabetic muscle infarction: report of two cases. Skeletal Radiol. 1997;26:122-127.
15. Van Slyke MA, Ostrov BE. MRI evaluation of diabetic muscle infarction. Magn Reson Imaging. 1995;13:325-329.

16. Keller DR, Erpelding M, Grist T. Diabetic muscular infarction. Preventing morbidity by avoiding excisional biopsy. Arch Intern Med. 1997;157:1611-1612.

17. Nuñez-Hoyo M, Gardner CL, Motta AO, Ashmead JW. Skeletal muscle infarction in diabetes: MR findings. J Comput Assist Tomogr. 1993; 17:986-988.

18. Sharma P, Mangwana S, Kapoor RK. Diabetic muscle infarction: atypical MR appearance. Skeletal Radiol. 2000;29:477-480.

19. Chason DP, Fleckenstein JL, Burns DK, Rojas G. Diabetic muscle infarction: radiologic evaluation. Skeletal Radiol. 1996;25:127-132.

20. Khan S, Al-Riyami D, Al-Ghailani M, Al-Dhuhli H. An underrecognized complication: diabetic myonecrosis. Oman Med J. 2009:24:228-230.

21. Yoo WH, Kim CH, Park JH, et al. Case report: diabetic muscle infarction presenting as knee arthralgia. Rheumatol Int. 2001;21:36-39.

22. Rocca PV, Alloway JA, Nashel DJ. Diabetic muscular infarction. Semin Arthritis Rheum. 1993;22:280-287.

23. Chow KM, Szeto CC, Wong TY, Leung FK, Cheuk A, Li PK. Diabetic muscle infarction: myocardial infarct equivalent. Diabetes Care. 2002;25:1895.

24. Umpierrez GE, Stiles RG, Kleinbart J, Krendel DA, Watts NB. Diabetic muscle infarction. Am J Med. 1996;101:245-250.

25. Qasem A, Tanha F, Briemberg H. A case of diabetic muscle infarction. Can J Neurol. 2009;36:651-653.

26. Muzaffar TH, Muzaffar FJ. A rare complication of diabetes mellitus in a 65-year-old man. J Diabetes Complications. 2009;23:438-440.

27. Ali A, Conti M, Massucco P, Trovati M. Diabetic muscle infarction associated with multiple autoimmune disorders, IgA deficiency and a catastrophically poor glycaemic control: a case report. Diabetes Nutr. 2003;16:134-137.

28. Theodoropoulou E, Chelioti E, Revenas K, Katsilambros N, Kostakis A, Boletis JN. Diabetic muscle infarction after kidney and pancreas transplantation case report and literature review. Transplant Proc. 2006;38:3147-3150.

29. Ahmed HN, Chhaya SK, Makdissi A, Zimmerman RS. Diabetic muscle infarction: case report of a rare complication. Am J Med. 2007;120:e3-e5.

30. Kermani T, Baddour LM. Diabetic muscle infarction mistaken for infectious cellulitis. Ann Intern Med. 2006;145:555-556.

31. Parmar MS. Diabetic muscle infarction. BMJ. 2009;338:b2271.

32. Naderi AS, Farsian FN, Palmer BF. Diabetic muscle necrosis. J Diabetes Complications. 2008;22:150-152.

33. Habib GS, Nashashibi M, Saliba W, Haj S. Diabetic muscular infarction: emphasis on pathogenesis. Clin Rheumatol. 2003;22:450-451.

34. Byars JA, Rosenberg EI. Diabetic myonecrosis in an orthotopic heart transplant recipient. J Heart Lung Transplant. 2007;26:549-552.

35. Virally M, Laloi-Michelin M, Médeau V, et al. Muscle infarction in a young woman with brittle type 1 diabetes. Diabetes Metab. 2007;33: 466-468.

36. Karalliedde J, Vijayanathan S, Thomas S. Painful foot drop; a presentation of diabetic muscle infarction. Diabet Med. 2010;27:958-959.

37. Reyes-Balaguer J, Solaz-Moreno E, Morata-Aldea C, et al. Spontaneous diabetic myonecrosis. Diabetes Care. 2005;28:980-981.

38. Joshi R, Vargas R. Diabetic muscle infarction in renal transplantation. Transplantation. 2004;77:321.

39. Chow KM, Szeto CC, Griffith JF, Wong TY, Li PK. Unusual muscle pain in two patients with diabetic renal failure. Hong Kong Med J. 2002;8:368-371.

40. Bjornskov EK, Carry MR, Katz FH, Lefkowitz J, Ringel SP. Diabetic muscle infarction: a new perspective on pathogenesis and management. Neuromuscul Disord. 1995;5:39-45.

41. Bingham C, Hilton DA, Nicholls AJ. Diabetic muscle infarction: an unusual cause of leg swelling in a diabetic on continuous ambulatory peritoneal dialysis. Nephrol Dial Transplant. 1998;13: $2377-2379$. 
42. Palmer GW, Greco TP. Diabetic thigh muscle infarction in association with antiphospholipid antibodies. Semin Arthritis Rheum. 2001;30:272-280.

43. Gulati A, Whitaker IS, Jaggard MKJ, et al. Diabetic muscle infarction: an underdiagnosed complication of a common disease. Practical Diabetes Int. 2005;22:27-31.

44. Madhan KK, Symmans P, Te Strake L, et al. Diabetic muscle infarction in patients on dialysis. Am J Kidney Dis. 2002;35:1212-1216.

45. Boulman N, Schapira D, Militianu D, et al. Diabetic muscle infarction. Isr Med Assoc J. 2003;5:669-670.

46. Lauro GR, Kissel JT, Simon SR. Idiopathic muscular infarction in a diabetic patient. Report of a case. J Bone Joint Surg Am. 1991;73: 301-304.

47. Barohn RJ, Kissel T. Case-of-the-month: painful thigh mass in a young woman: diabetic muscle infarction. Muscle Nerve. 1992;15: $850-855$.

48. Trujillo-Santos AJ, Alcalá-Pedrajas JN, et al. Mujer de 70 años con dolor e inflamación en pantorrilla derecha. [A 70-year-old woman with right calf pain and inflammation]. Rev Clin Esp. 2001;201:153-154. Spanish.

49. Damron TA, Levinsohn EM, McQuail TM, Cohen H, Stadnick M, Rooney M. Idiopathic necrosis of skeletal muscle in patients who have diabetes. Report of four cases and review of the literature. J Bone Joint Surg Am. 1998;80:262-267.

50. Barton KL, Palmer BF. Bilateral infarction of the vastus lateralis muscle in a diabetic patient: a case report and review of the literature. J Diabetes Complications. 1993;7:221-223.

51. Ostrov BE, Van Slyke MA, Ferriss JA. Diabetic muscle infarction: an underappreciated cause of a painful swollen extremity. Evaluation with magnetic resonance imaging. J Clin Rheumatol. 1995;1:40-45.

52. Chow CC, Mo KL, Wong KS. A woman with swollen legs. Lancet. 2002;359:402.
53. Welck MJ, Vetpillai P, Balaji V, Jennings R, Goodier WD. Recurrent multifocal diabetic myonecrosis: a cause of severe extremity pain in a diabetic patient. Ann R Coll Surg Engl. 2013;95:e5-e6.

54. Rastogi A, Bhadada SK, Saikia UN, Bhansali A. Recurrent diabetic myonecrosis: a rare complication of a common disease. Indian J Med Sci. 2011;65:311-315.

55. Arroyave JA, Aljure DC, Canas CA, Velez JD, Abadia FB. Diabetic muscle infarction: two cases: one with recurrent and bilateral lesions and one with usual unilateral involvement. J Clin Rheumatol. 2013;19:126-128.

56. Kim SW, Kim SS. Myonecrosis of paralumbar spine muscle. Spine (Phila Pa 1976). 2011;36:E1162-E1165.

57. Kapur S, McKendry RJ. Treatment and outcomes of diabetic muscle infarction. J Clin Rheumatol. 2005;1:8-12.

58. Schattner A, Zornitzki T, Adi M, Friedman J. Painful swelling in the thigh: diabetic muscle infarction. CMAJ. 2009;180:72-74.

59. Banker BQ, Chester CS. Infarction of thigh muscle in the diabetic patient. Neurology. 1973;23:667-677.

60. Brower RG. Consequences of bed rest. Crit Care Med. 2009;37: S422-S428.

61. Taira M, Komiya I, Taira T, et al. A case of diabetic muscle infarction in Japan. Diabet Med. 1998;15:1065-1067.

62. Sagar M, Bowerfind WM, Wigley FM. A man with diabetes and a swollen leg. Lancet. 1999;353:116.

63. Rajkumar V, Ragatzki P, Sima A, Levy J. Enhanced platelet aggregation, high homocysteine level, and microvascular disease in diabetic muscle infarctions: implications for therapy. Endocrine. 1999;11:57-60.

64. Huang E, Ho CF, Yip PK, Lin YC, Tsai CF. Diabetic muscle infarction in a patient with acute embolic stroke. Neurol Sci. 2010;31:345-347.

65. Litvinov IV, Radu A, Garfield N. Diabetic muscle infarction in a 57 year old male: a case report. BMC Res Notes. 2012;5:701.
Open Access Rheumatology Research and Reviews

\section{Publish your work in this journal}

Open Access Rheumatology Research and Reviews is an international, peer-reviewed, open access journal, publishing all aspects of clinical and experimental rheumatology in the clinic and laboratory including the following topics: Pathology, pathophysiology of rheumatological diseases; Investigation, treatment and management of rheumatological

\section{Dovepress}

diseases; Clinical trials and novel pharmacological approaches for the treatment of rheumatological disorders. The manuscript management system is completely online and includes a very quick and fair peerreview system, which is all easy to use. Visit http://www.dovepress.com/ testimonials.php to read real quotes from published authors. 